\title{
Exploring attributes of effective teachers - student perspectives from an Indian medical school
}

\author{
Ciraj $A M^{1}$, Reem Rachel Abraham ${ }^{2}$, Vinod Pallath ${ }^{1}$, K.Ramnarayan ${ }^{3}$, \\ Asha Kamath $^{4}$, Ramachandra Kamath
}

\begin{abstract}
Introduction: Attributes of an effective teacher is a passionate area of research for medical educators. Teaching at Melaka Manipal Medical College (MMMC), Manipal University, India, is assessed periodically as a part of the institution's program evaluation process. The present study was undertaken to determine the highly rated attributes of a medical teacher, as felt by three batches (preclinical, para-clinical and clinical batch) of medical students at MMMC.

Methods: A questionnaire focusing on twelve attributes of effective teaching was developed and administered to three batches of students. Students were requested to select the five most important attributes from the questionnaire and rank them accordingly as $1^{\text {st }}, 2^{\text {nd }}, 3^{\text {rd }}, 4^{\text {th }}$ and $5^{\text {th }}$. The responses were analyzed using cross tabulation and percentages of the grades provided by the participants were reported for each of the batch.

Results: The ability of a teacher to motivate and inspire students was rated to be the best attribute of an effective teacher. Students also felt that defining objectives and clarifying concepts was an important quality that medical teachers should possess. The importance of being an effective communicator was also emphasized.

Discussion: The present study underpins the need for a healthy teacher-student relationship in medical schools. Communication with international students in an Indian scenario may be a challenging task, keeping in mind the diverse cultural background of students. Probing qualities that students identify with an effective teacher may help us respond to these challenges.
\end{abstract}

Keywords: effective teacher attributes, international medical students

\section{Introduction}

Medical schools across the globe give substantial importance to effective teaching. A medical teacher is no longer considered an information provider, but also, an assessor

\footnotetext{
${ }^{1}$ Department of Microbiology, Melaka Manipal Medical College, Manipal Campus

${ }^{2}$ Department of Physiology, Melaka Manipal Medical College, Manipal Campus

${ }^{3}$ Department of Pathology, Melaka Manipal Medical College, Manipal Campus

${ }^{4}$ Department of Community Medicine, Kasturba Medical College

${ }^{5}$ Department of Public Health

Manipal University, Karnataka, India

Corresponding author:

Dr. Reem Rachel Abraham

Department of Physiology, Melaka Manipal Medical

College, Manipal Campus, Manipal University

Karnataka, India

Email: reemabraham@yahoo.com
}

planner, mentor and a role model (Harden \& Crosby, 2000). The multiple roles that a teacher is expected to play in the educational environment makes the task of describing what it means to be a good teacher, quite difficult (Das, et al., 1996). The overemphasis attributed to 'scholarly works' over teaching in the recent times have made this task even more challenging.

In many medical schools, teaching is given due weightage by rewarding good teachers using anonymous student feedbacks. Though commonly used in medical education these feedbacks are one of the most criticized tools to evaluate teacher effectiveness. Faculty members who are very critical about evaluation using student feedbacks, agree on the need for student input in the assessment of teaching.

Studies in the past have reported the attributes of a good teacher as being knowledgeable, enthusiastic (Ambrozy et al., 1997) and being sensitive to student needs. Personal traits of 
teachers like approachability and friendly nature were also rated high when compared to academic issues (Mclean, 2001). The fact is that the teacher-student relationship is no longer bound within the classroom, but extends much beyond that. Effective teacherstudent relationship not only impinges upon academic development of a student, but also on the personal and professional growth.

There has been a considerable shift in the medical curriculum by transforming it from teacher-centered to student-centered one. Also, efforts towards making students more responsible for their learning is being tried by introducing strategies like case based and problem based learning. Teachers are also encouraged to make their deliberations more active by involving students in the learning process and by incorporating advances in technology. Additionally, attempts have been made in redefining the role of teachers in creating a safe and nonthreatening educational environment that would promote active learning. This calls for being an effective mentor and facilitator. It is unfortunate that in our settings many are not even aware about their multiple roles in these changed environments.

Medical schooling in India remains largely compartmentalized with pre and para-clinical training in the initial years followed by clinical training and compulsory internship. Studies probing the qualities of a good teacher in clinical settings have been conducted (Sutkin et al., 2008), information with reference to pre and para-clinical teaching is scarce.

Though It may be convenient to perceive, medical students irrespective of their level of training would consider attributes of an effective a medical teacher to be same, experimental evidence to support this view is lacking. It is in this context that we conceived this study with an intention to analyze if the level of training influences medical students' opinion on attributes they link with an effective teacher.

The objective of this study was to determine the highly rated attributes of a medical teacher, as felt by medical students of MMMC. By compiling perceptions from three different batches of medical students who were at different levels of their medical training, we also tried analyzing if the level of training had any influence on formulating attributes which they consider integral to being an effective teacher.

\section{Method}

This study was conducted at Melaka Manipal Medical College (MMMC), Manipal University, India which offers a Bachelor of Medicine and Bachelor of Surgery (MBBS) program in a twinning mode. The program envisages two and a half years training each at Manipal Campus, India and Melaka Campus, Malaysia. During their first year (preclinical phase) students studied anatomy, physiology and biochemistry. The second year (para-clinical phase) is devoted to microbiology, pathology and pharmacology. Out of the remaining three years (clinical phase) six months of clinical training is conducted in India and the rest (two and half years) in Melaka, Malaysia.

The present study was conducted among three batches of students at MMMC, after approval from the Institutional Review Board. The first batch (hereafter referred to as the pre-clinical batch) comprised students in their first year of medical training whereas the second batch (hereafter referred to as paraclinical batch) near completing of their first two years of training. The third batch of students included students in the final semester undergoing clinical training in Malaysia.

After a thorough literature review, a questionnaire focusing on twelve attributes of effective teaching (Table 1) was developed. Content validity of the questionnaire was determined by seeking opinions of medical education experts. The questionnaire was administered to the pre and para-clinical batches on separate days after a regular lecture class. The clinical batch students were requested to respond to the questionnaire during their clinical postings.

Students were informed regarding the purpose of the study and assured of the confidentiality of the responses. They were requested to select the five most important attributes from the questionnaire and rank them accordingly as $1^{\text {st }}, 2^{\text {nd }}, 3^{\text {rd }}, 4^{\text {th }}$ and $5^{\text {th }}$. The responses were analyzed using cross tabulation and percentages of the grades provided by the participants were reported for each of the batches.

\section{Results}

A total of 321 students participated in this study. There were who112 belonged to pre and 114 to para clinical batch. The number of students in the clinical term who participated in this study was 95 . 
All the twelve features in the questionnaire (Table 1) figured among the first five attributes chosen by the clinical and para clinical batch. The first three attributes mentioned in the questionnaire ( $A 1, A 2$ and $A 3)$ received the highest ratings and were considered the most important attributes by students from all the three batches. The ability of a teacher to motivate and inspire students was rated to be the best attribute of an effective teacher. Next to this, medical students also felt that an effective teacher would define objectives and clarify concepts. The importance of being an effective communicator was rated third among the twelve attributes provided in the questionnaire.

Table 1: Twelve attributes of an effective teacher provided in the questionnaire. Students were requested to select the five most important attributes and rank them $1^{\text {st }}$ to $5^{\text {th }}$

\begin{tabular}{ll}
\hline & \multicolumn{1}{c}{ Attributes of an effective teacher } \\
\hline A1 & Motivates and inspires students \\
A2 & Defines objectives and clarifies concepts \\
A3 & Communicates effectively \\
A4 & Enthusiastic about teaching the course \\
A5 & Encourages student learning \\
A6 & Accessible to students outside the class hours \\
A7 & Links basic science to clinical practice and vice versa \\
A8 & Shows respect to students/staff /patients \\
A9 & Discusses values and attitudes \\
A10 & Provides notes/handouts and study guides \\
A11 & Creative and resourceful \\
A12 & Encourages a multidisciplinary approach \\
\hline
\end{tabular}

The medical students in their first year of schooling wished their teachers to be enthusiastic about teaching their course and to be creative and resourceful. However, in spite of being new to the environment it was found that accessibility of teachers outside the class hours was significant from this batch. Second year students wanted their teachers to provide notes, handouts and study guides. Clinical students besides identifying the need to link basic and clinical sciences also rated their teacher's ability to show respect to students, staff and patients as an important attribute. The detailed descriptions of the ratings are provided in Tables 2 and 3.

\section{Discussion}

Teaching is assessed periodically as a part of our institution's program evaluation process. In this context, the present study was undertaken to determine the five highly rated attributes of a medical teacher, three batches of medical students at MMMC. The batches chosen were at different levels of their training in the medical school. What makes a good teacher may be different for different students and may vary with the occasion (Sutkin et al., 2008). But it is accepted that students' opinions of effective teaching will bring about changes in teachers' attitudes (Rajeev \& Raghuveer, 2007), so that these qualities could be engendered in teachers.

Our study found that no matter what level of training they were in, medical students valued the teacher's ability to motivate and inspire as the most important attribute. It is an accepted fact that medical education is a stressful experience and encouragement provided by teachers will make a difference. This is where teachers will have to walk that extra mile to function as a mentors or facilitators. The findings are common with previous reports that identify effective teachers to be supportive to the students (Sutkin et al., 2008). This should be an eye opener for many of our teachers who believe that their role as teachers is confined only to academic deliberations. 
Like most medical schools in the region, the practice at MMMC was to provide a syllabus which outlines only the core areas in the curriculum. With many disciplines to master concurrently, the absence of a scheme that specifies learning objectives often adds to the pressure of medical students. We initiated the task of identifying the core areas in the curriculum and formulate learning objectives accordingly. It is clear that by doing so a substantial reduction in student burden was achieved which made them rate this attribute of teachers significantly higher than many other qualities cited in the questionnaire.

Table 2: Students' perceptions of the three batches on the attributes of an effective medical teacher (in percentages)

\begin{tabular}{|c|c|c|c|c|c|c|c|c|c|c|c|c|c|c|c|}
\hline & \multicolumn{3}{|c|}{ First choice } & \multicolumn{3}{|c|}{ Second choice } & \multicolumn{3}{|c|}{ Third choice } & \multicolumn{3}{|c|}{ Fourth choice } & \multicolumn{3}{|c|}{ Fifth choice } \\
\hline & Pre & Para & Clinics & Pre & Para & clinics & Pre & Para & clinics & Pre & Para & clinic & Pre & Para & clinics \\
\hline A1 & 17.7 & 21.1 & 35.5 & 14.6 & 11.4 & 6.5 & 9.4 & 13.8 & 14.5 & 9.4 & 13.8 & 5.6 & 14.6 & 15.4 & 12.1 \\
\hline A2 & 22.9 & 16.3 & 8.1 & 17.7 & 19.5 & 13.7 & 8.3 & 10.6 & 5.6 & 13.5 & 8.9 & 9.7 & 9.4 & 8.1 & 7.3 \\
\hline A3 & 21.9 & 30.1 & 13.7 & 20.8 & 22 & 12.1 & 17.7 & 17.1 & 16.1 & 12.5 & 11.4 & 11.3 & 8.3 & 7.3 & 13.7 \\
\hline A4 & 10.4 & 17.1 & 8.9 & 19.8 & 8.1 & 8.9 & 14.6 & 8.9 & 5.6 & 7.3 & 7.3 & 12.1 & 4.2 & 5.7 & 7.3 \\
\hline A5 & 3.1 & 0 & 2.4 & 8.3 & 4.1 & 12.1 & 12.5 & 4.1 & 11.3 & 4.2 & 4.9 & 8.1 & 13.5 & 10.6 & 8.1 \\
\hline A6 & 2.1 & 0 & 3.2 & 1.0 & 5.7 & 11.3 & 9.4 & 5.7 & 12.1 & 6.3 & 10.6 & 5.6 & 2.1 & 7.3 & 12.1 \\
\hline A7 & 8.3 & 3.3 & 13.7 & 14.6 & 8.1 & 11.3 & 4.2 & 10.6 & 11.3 & 13.5 & 9.8 & 7.3 & 8.3 & 14.6 & 13.7 \\
\hline A8 & 11.5 & 3.3 & 10.5 & 9.4 & 2.4 & 2.4 & 8.3 & 2.4 & 10.5 & 13.5 & 6.5 & 11.3 & 9.4 & 12.2 & 11.3 \\
\hline A9 & 2.1 & 1.6 & 3.2 & 10.4 & 0.8 & 6.5 & 2.1 & 0.8 & 4.8 & 1 & 4.9 & 3.2 & 2.1 & 4.1 & 6.5 \\
\hline A10 & 16.7 & 2.4 & 3.2 & 6.3 & 7.3 & 4.8 & 12.5 & 13 & 4.8 & 12.5 & 11.4 & 11.3 & 14.6 & 4.1 & 15.3 \\
\hline A11 & 5.2 & 6.5 & 3.2 & 9.4 & 11.4 & 5.6 & 6.3 & 17.1 & 7.3 & 5.2 & 14.6 & 12.9 & 14.6 & 13.0 & 11.3 \\
\hline A12 & 5.2 & 8 & 2.4 & 7.3 & 8 & 5 & 2.1 & 0.8 & 12.9 & 1 & 5.7 & 4.8 & 5.2 & 2.4 & 6.5 \\
\hline
\end{tabular}

Table 3: Cumulative percentages of the first five choices of the three batches

\begin{tabular}{ccccc}
\hline Item & $\begin{array}{c}\text { Batch 16 } \\
\text { (paraclinical) }\end{array}$ & $\begin{array}{c}\text { Batch 20 } \\
\text { (preclinical) }\end{array}$ & $\begin{array}{c}\text { Melaka } \\
\text { (clinical) }\end{array}$ & $\begin{array}{c}\text { Average } \\
\text { percentage }\end{array}$ \\
\hline A1 & 65.6 & 75.6 & 74.19 & 71.79 \\
A2 & 71.8 & 71.5 & 44.3 & 62.53 \\
A3 & 81.2 & 87.8 & 66.9 & 78.6 \\
A4 & 56.2 & 47 & 43.2 & 48.8 \\
A5 & 41.6 & 21.9 & 41.9 & 35.1 \\
A6 & 20.8 & 29.26 & 41.93 & 30.66 \\
A7 & 48.95 & 46.34 & 57.25 & 50.84 \\
A8 & 52.08 & 33.3 & 54.83 & 46.7 \\
A9 & 17.7 & 12.19 & 20.16 & 16.68 \\
A10 & 62.5 & 38.21 & 41.12 & 47.27 \\
A11 & 38.5 & 62.6 & 39.5 & 46.8 \\
A12 & 20.83 & 10.56 & 32.25 & 21.21 \\
\hline
\end{tabular}


Ability to communicate well is considered a core competency for every teacher (Azer, 2005). Effective communicators are adored by students and often rated best among their teachers. Efforts to impart communication skills as a part of the faculty development programs is lacking in most medical schools in this region. Communication with international students in an Indian scenario is a challenging task, keeping in mind the diverse cultural background of the students. Faculty development programs should focus on programs that help medical teachers build up requisite communication skills.

Students belonging to para-clinical batch suggested that the practice of providing notes, handouts and study guides are important for considering a medical teacher to be effective. This observation cannot be generalized as it specifically relates to our academic setting. As a part of curricular innovations, the medical school during its second year (para-clinical) had offered strategies like case based and problem based learning with the intention to promote student-centered learning. These strategies revolved around the concept of small group learning and demanded the 'facilitation effect' from faculty by forcing them to forego a large chunk of didactic exercises. This would have led to the apprehension of students being left alone with too much content to learn on their own which has manifested their interest in procuring handouts and study guides. However evidence of a positive impact on learning by providing notes and handouts does exist in medical education literature (Kiewrac et al., 1998).

Showing respect to students, peers and patients figured among first five attributes in the opinion of students belonging to the clinical batch. The students view that an effective teacher should give due respect to students, peers and patients suggests that it is not only your expertise that students value but also the way they interact with the people around you on a regular basis. The findings of Buchel and Edwards (2005), which reports respect for independency as clinicians as an important attribute for a medical teacher as felt by family residents also points towards a similar student attitude.

It is not surprising for the students during their formative years (pre-clinical batch) to expect their teachers to be enthusiastic about teaching their course besides being creative and resourceful. Having joined the medical school for less than six months their views are probably a reflection of educational practices they have experienced and not necessarily reflect the environment prevailing in the medical school.

Linking the basic science to clinical practice and vice versa was considered one of the most important attribute of an effective teacher by the clinical batch students. This partly reflects the nature of our first and second year curriculum which is strictly compartmentalized with a delivery that is predominantly discipline based. In such situations, students often find it difficult to relate basic science knowledge studied earlier to the cases they encounter. Revisiting the fundamentals is the only viable option. Spiraling in the curriculum and use of strategies like e-learning are seriously being thought as a possible alternative.

Students' perceptions of effective teaching will have a bearing on teacher's attitudes. This data if made available for faculty members would help them in self-analysis. The novice may use it as a route map for professional development. A veteran teacher may equally find it helpful as it provides an update of student perceptions on teacher effectiveness. This is because perceptions are heavily influenced based on the educational environment.

Previous studies on teacher effectiveness emphasize the usefulness of such studies in faculty development (Martens et al., 2009). Findings of the present study will be used for planning and developing continuing education programs for the medical faculty.

No matter how difficult it would be, if a desirable attribute/quality can be introduced and inculcated through faculty development programs, it is worthwhile.

\section{Conclusion}

Besides stressing the need for nurturing good teacher-student relationship the study emphasizes the multiple roles a teacher will have to perform in order to be considered effective by medical students. There were no significant differences in opinion on the major attributes of an effective teacher between students who were at different levels of their medical training. 


\section{References}

Ambrozy, D.M., Irby, D.M., Bowen, J.L., Burack, J.H., Carline, J.D. \& Stritter, F.T. (1997) Role models' perceptions of themselves and their influence on speciality choices, Acad Med, 72, pp.1119-1121.

Azer, S.A. (2005) The qualities of a good teacher: how can they be acquired and sustained?. J Royal Soc Med, 98, 2, pp.67-69.

Buchel, T.L. \& Edwards, F.D. (2005) Characteristics of effective clinical teachers. Family Medicine, 37, 1, pp.30-35.

Das, M. et al., (1996) Student and faculty perceptions the characteristics of an ideal teacher in a classroom setting, Medical Teacher, 18, pp.141-146.

Harden, R.M. \& Crosby, J.R. (2000) AMEE guide No 20: the good teacher is more than a lecturer - the twelve roles of the teacher, Medical Teacher; 22, pp.334-347.
Kiewra, K.A., DuBois, N.F., Christian, D. \& McShane, A. (1988) Providing study notes: comparison of three types of notes for review, $J$ Educ Psychol, 80, pp.595-597.

Martens, M.J.C., Duvivier, R.J., van Dalen ,J., Verwijnen, G.M., Scherpbier, A.J.J.J.A. \& van der Vleuten, C.P.M. (2009) Student views on the effective teaching of physical examination skills: a qualitative study. Med Educ, 43, pp. 184-191.

Mclean, M. (2001) Qualities attributed to an ideal educator by medical students: should faculty take cognizance ? Med Teach, 23, pp. 367370.

Rajeev, A. \& Raghuveer, C.V. (2007) The assessment of a good teacher: Student's paradigm, KUMJ, 5, pp. 264-267.

Sutkin, G., Wagner, E., Harris, I. \& Schiffer, R. (2008) What makes a good clinical teacher in medicine? A review of the literature, Acad Med 83, pp. 452-466. 